\title{
ANALISIS USABILITY APLIKASI PENGISIAN KRS ONLINE STMIK XYZ PALEMBANG MENGGUNAKAN USE QUESTIONNAIRE
}

\author{
Lisa Amelia ${ }^{1}$, Dien Novita ${ }^{2}$ \\ Komputerisasi Akuntansi ${ }^{1}$, Sistem Informasi ${ }^{2}$ \\ ${ }^{1,2}$ STMIK Global Informatika MDP \\ Jalan Rajawali No 14 Palembang 30113 \\ Email: lisa@mdp.ac.id ${ }^{1}$, dien@mdp.ac.id ${ }^{2}$
}

\begin{abstract}
ABSTRAK
Aplikasi pengisian KRS online di STMIK XYZ Palembang ini baru diterapkan, sehingga perlu dilakukan analisis agar mendapatkan masukan untuk lebih meningkatkan kualitas dari aplikasi. Analisis dalam penelitian ini adalah analisis usability dan melihat hubungan antara variabel bebas yaitu variabel usefulness, ease of use, dan ease of learning terhadap variabel terikat, yaitu satisfaction secara simultan maupun parsial. Pengukuran usability mangadopsi USE questionnaire, menggunakan SPSS dalam mengolah data yang melibatkan 87 responden dari 3 program studi di STMIK XYZ Palembang. Hasil analisis menunjukkan nilai persentase kelayakan sebesar $85,89 \%$ artinya hasil pengukuran usability aplikasi KRS secara online memiliki nilai sangat layak. Selain itu juga, dibuktikan dari pengujian hipotesis bahwa ada pengaruh yang signifikan antara variabel usefulness, ease of use, dan ease of learning terhadap satisfaction secara simultan. Secara parsial, variabel usefulness dan ease of use berpengaruh signifikan terhadap satisfaction, sedangkan variabel ease of learning tidak berpengaruh terhadap satisfaction. Faktor dominan yang mempengaruhi kepuasan user dalam menggunakan aplikasi pengisian KRS online adalah ease of use (kemudahan penggunaan) dengan nilai rata-rata 46,4. Hasil penelitian, merekomendasikan perlunya meningkatkan minat user untuk mempelajari dan memberikan koreksi atas kekurangan aplikasi tersebut agar menjadi lebih baik lagi.
\end{abstract}

Kata Kunci : KRS online, usability, satisfaction, USE questionnaire, SPSS.

\section{ABSTRACT}

The online KRS application at STMIK XYZ Palembang has just been applied, so the analysis needs to be done to get contribution to improve the quality of the application. The analysis in this study is usability analysis and see the relationship between independent variables namely usefulness, ease of use, and ease of learning variables and the dependent variable, namely satisfaction simultaneously or partially. Usability measurements adopted the USE questionnaire, using SPSS in processing data involving 87 respondents from 3 programs at STMIK XYZ Palembang. The results of the analysis show the percentage of feasibility is $85,89 \%$, which means that the usability measurement of the online KRS application have a very acceptable. In addition, it is also proven by testing the hypothesis that there is a significant influence between the variables of usefulness, ease of use, and ease of learning on satisfaction simultaneously. Partially, usefulness and ease of use variables have a significant effect on satisfaction, while the ease of learning variable does not affect satisfaction. The dominant factor that influences user satisfaction in using the online KRS application is ease of use with an average value of 46,4. The results of the study, recommend the need to increase user interest to learn and provide corrections to the shortcomings of the application to be better.

Keywords : online KRS, usability, satisfaction, USE questionnaire, SPSS.

\section{PENDAHULUAN}

Didasari awalnya keinginan untuk berpartisipasi dalam pembangunan negara Republik Indonesia terutama pembangunan manusia yang berintegritas serta memiliki kemampuan di bidang Teknologi Informasi, maka pemilik STMIK XYZ Palembang mengembangkan lembaga pendidikan tinggi 
berbentuk sekolah tinggi berbasis komputer. Sekolah tinggi ini memiliki tiga program studi S1 yaitu Program Studi Sistem Informasi (SI) dan Program Studi Teknik Informatika (TI) dan satu program D3 yaitu Program Studi Komputerisasi Akuntansi (KA).

Untuk mendukung sistem perkuliahan, tersedia 24 ruang kelas dimana setiap kelas telah di lengkapi dengan LCD projector, Smart Board/Onfinity, dan pendingin udara. Selain itu juga setiap ruangan dilengkapi dengan satu buah unit komputer dan akses internet untuk menunjang sistem perkuliahan, adanya internet corner, wifi gratis, dan adanya perpustakaan yang menyediakan beberapa unit komputer yang dapat digunakan untuk mengakses informasi dari internet. Selain itu STMIK XYZ membangun aplikasi berbasis web untuk mendukung proses perkuliahan, yaitu sistem informasi pengisian silabus, sistem informasi akademik, dan sistem pengisian Kartu Rencana Studi (KRS) secara online.

Pengisian KRS dilakukan di setiap awal perkuliahan semester gasal dan genap oleh setiap mahasiswa. Awalnya pengisian KRS tidak dilakukan secara online tetapi dengan intranet lokal, mahasiswa secara langsung datang ke kampus dan pengisian dijadwalkan oleh lembaga sebelum mulai perkuliahan. Tetapi hal ini mendapat banyak keluhan dari mahasiswa, antara lain tidak dapat mengikuti jadwal yang ditentukan karena berada di luar kota, selain itu saat proses pengisian KRS sering terjadi crowded saat mahasiswa masuk ke ruang laboratorium untuk pengisian KRS. Hal inilah yang mendasari perubahan sistem pengisian KRS secara online, yang baru diterapkan sejak dua tahun yang lalu.

Pengisian KRS secara online di STMIK XYZ Palembang ini belum pernah dilakukan evaluasi tentang penggunaaannya, apakah sistem yang baru lebih baik dari sistem sebelumnya. Dalam pengembangan sebuah sistem, salah satu hal terpenting adalah usability yang baik. Secara umum usability adalah kondisi dimana seseorang dapat mampu menggunakan suatu sistem yang dalam hal ini sistem pengisian KRS secara online sehingga tujuan tercapai.

\subsection{Pengertian Usability}

Terdapat berbagai pengertian usability dari berbagai sumber. Beberapa pengertian usability yang dikemukakan adalah sebagai berikut :
1. Menurut JeffAxup (2004) dalam [1] adalah sebuah ukuran sebuah karakteristik yang mendeskripsikan seberapa efektif seorang pengguna dalam berinteraksi dengan suatu produk. Usability juga merupakan ukuran seberapa mudah suatu produk bisa dipelajari dengan cepat dan seberapa mudah suatu produk bisa digunakan.

2. Menurut International Organization for Standardization (1998), usability dapat didefinisikan sebagai tingkat di mana sebuah produk bisa digunakan oleh pengguna tertentu untuk mencapai tujuan tertentu dengan efektif, efisien, dan memperoleh kepuasan dalam konteks penggunaannya [2].

3. Menurut [3] usability digunakan untuk mengukur tingkat pengalaman pengguna ketika berinteraksi dengan produk sistem. Secara umum, usability mengacu kepada bagaimana pengguna bisa memperlajari dan menggunakan produk untuk memperoleh tujuannya, dan seberapa puas mereka terhadap penggunaannya.

4. Badre (2002) memberikan pengertian usability testing atau uji ketergunaan adalah mengukur efisiensi, kemudahan dipelajari, dan kemampuan untuk mengingat bagaimana berinteraksi tanpa kesulitan atau kesalahan. Menurut Nielson (2000), usability testing adalah suatu attribut untuk menilai seberapa mudah interface website digunakan [4].

5. Dix et al, (2004) dalam [5] memberikan definisi sistem yang dapat membantu pengguna untuk menyelesaikan permasalahan mereka adalah sistem yang:

a. Berguna (useful): sistem yang berfungsi seperti yang diinginkan oleh penggunanya.

b. Dapat digunakan (usable): sistem yang mudah dioperasikan

c. Digunakan (used): sistem yang memotivasi user atau penggunanya menggunakannya, menarik bagi user, menyenangkan, dan lain-lain.

6. Jacob Nielsen (2003) dalam [6], usability adalah atribut kualitas yang menunjukkan seberapa mudah suatu antarmuka digunakan. Terdiri atas lima komponen kualitas, yaitu:

a. Learnability: dapat mengukur semudah apa user dapat mempelajari cara penggunaan produk tersebut untuk pertama kali. 
b. Efficiency: mengukur secepat apa user dapat melakukan tugasnya.

c. Memorability: sejauh mana user dapat mengingat langkah-langkah atau proses yang dilakukan dalam mencapai tujuannya.

d. Errors: sebanyak apa user melakukan error, dan sejauh mana akibat error tersebut, serta apakah mudah bagi user untuk mengatasi error tersebut.

e. Satisfaction: bagaimana perasaan user ketika menggunakan produk atau tanggapan terhadap desain produk secara keseluruhan.

7. Palmer (2002) dalam [5], mengamati atribut kualitas lain dari kebergunaan, yaitu: waktu download, navigabilitas, interaktifitas, responsifitas, dan kualitas konten.

Inti utama usability adalah apakah aplikasi atau produk telah sesuai dengan keinginan user.

\subsection{Pengukuran Usability}

Mengukur usability berarti mengukur efektifitas, efisiensi, dan kepuasan user[7]. Untuk itu dapat dilakukan dua cara, yaitu:

1. Mengandalkan asumsi pembuat program/diri sendiri.

2. Menggunakan usability metric.

Hasil pengukuran usability dapat dimanfaatkan untuk beberapa hal berikut, yaitu:

1. Mendapatkan masukan dari data, lebih obyektif daripada pendapat sendiri.

2. Dapat digunakan untuk membandingkan usability dua produk.

3. Dapat mengklasifikasi permasalahan (jika ada).

4. Membuat prediksi penggunaan produk yang sebenarnya.

5. Memberikan ilustrasi pada manajemen berdasarkan fakta [8].

Pada umumnya, pengukuran usability dilakukan menggunakan serangkaian kuisioner. Pada saat ini terdapat beberapa jenis kuisioner yang dapat digunakan untuk mengukur usability, seperti:

1. Perceived Usefulness and Ease of Use (PUEU), merupakan paket kuisioner yang dirilis oleh IBM yang terdiri atas 12 item instrument pengukuran.

2. WAMMI untuk mengukur website dan inventory.

3. Computer System Usability Questionnaire (CSUQ), merupakan paket kuisioner yang juga dirilis oleh IBM yang terdiri atas 19 item instrument pengukuran.

4. Measurement of Usability of Multi Media Software (MUMMS)

5. USE (Usefulness, Satisfaction, and Ease of use), yang terdiri atas 30 item instrument pengukuran serta beberapa paket kuisioner lainnya [9].

\section{METODE PENELITIAN}

\subsection{Tahapan Penelitian}

Tahapan yang dilakukan dalam penelitian ini, ditunjukkan Gambar 1 berikut.

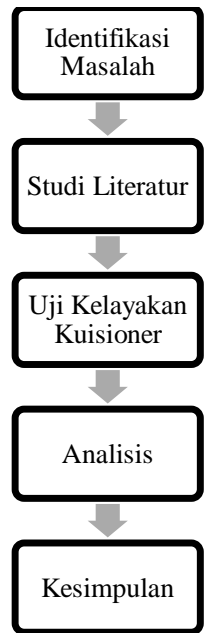

Gambar 1 Tahapan Penelitian

\subsection{Variabel-Variabel Penelitian}

Variabel penelitian adalah suatu atribut atau sifat atau nilai dari orang, objek, atau kegiatan yang mempunyai variasi tertentu yang ditetapkan oleh peneliti untuk mempelajari dan kemudian ditarik kesimpulannya [10].

Penelitian ini terdiri dari dua variabel yang akan diteliti, yaitu variabel bebas dan variabel terikat. Yang menjadi variabel bebas (independent) adalah variabel usefulness, variabel ease of use, dan variabel ease of learning, sedangkan variabel satisfaction dikategorikan sebagai variabel terikat (dependent).

\subsection{Hipotesis}

Penelitian ini menggunakan desain kausal yang bertujuan untuk menganalisis hubungan antara satu variabel dengan variabel lainnya. Desain kausal digunakan untuk menganalisis secara empiris variabel-variabel yang berpengaruh terhadap kepuasan pengguna (user satisfaction), yakni variabel usefulness, 
variabel ease of use, dan variabel ease of learning berdasarkan kuesioner USE berdasarkan penelitian [11]. Desain kausal mengacu pada [12] dalam model penelitian seperti ditunjukkan Gambar 2.

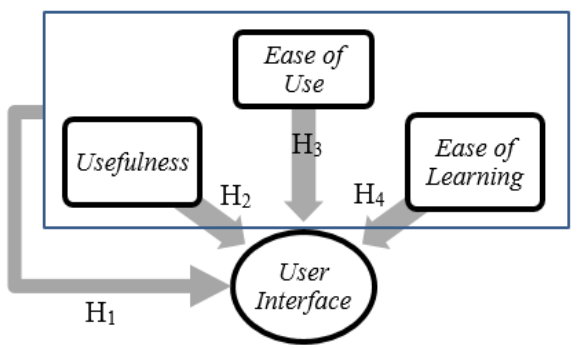

Gambar 2 Model Penelitian

Berdasarkan Gambar 2 dapat disusun hipotesis sebagai berikut:

$\mathrm{H}_{0}$ : Tidak ada pengaruh yang signifikan antara variabel bebas, yaitu variabel usefulness, variabel ease of use, dan variabel ease of learning terhadap variabel terikat yaitu variabel satisfaction yang dilakukan secara simultan atau parsial.

$\mathrm{H}_{1}$ : Ada pengaruh yang signifikan antara variabel bebas yaitu variabel usefulness, variabel ease of use, dan variabel ease of learning terhadap variabel terikat yaitu variabel satisfaction yang dilakukan secara simultan.

$\mathrm{H}_{2}$ : Ada pengaruh yang signifikan antara variabel usefulness terhadap variabel terikat yaitu variabel satisfaction.

$\mathrm{H}_{3}$ : Ada pengaruh yang signifikan antara variabel ease of use terhadap variabel terikat yaitu variabel satisfaction.

$\mathrm{H}_{4}$ : Ada pengaruh yang signifikan antara variabel ease of learning terhadap variabel terikat yaitu variabel satisfaction.

\subsection{Populasi dan Sampel}

Populasi dalam penelitian ini adalah user aplikasi KRS online STMIK XYZ Palembang, yaitu mahasiswa aktif STMIK XYZ Palembang yang berjumlah 673 orang. Dari seluruh populasi, diambil beberapa sampel untuk menjadi responden. Teknik sampling menggunakan metode simple random sampling yaitu pengambilan sampel dilakukan secara acak sehingga seluruh anggota populasi mempunyai probabilitas yang sama untuk dijadikan sampel. Jadi, dengan menggunakan metode simple random sampling, yang berhak menjadi responden adalah seluruh mahasiswa aktif STMIK XYZ Palembang dari program studi Sistem Informasi (SI), Teknik Informatika (TI), dan Komputerisasi Akuntansi (KA). Sedangkan penentuan ukuran sampel dilakukan dengan menggunakan rumus Slovin seperti pada (1).

$$
n=\frac{N}{1+N(e)^{2}}
$$

Keterangan:

$\mathrm{n}=$ jumlah sampel

$\mathrm{N}=$ jumlah populasi

$\mathrm{e}=$ standar kesalahan (error) sebesar $10 \%$

Berdasarkan rumus Slovin (1), maka besarnya jumlah sampel (n) jika jumlah populasi (N) sebanyak 673 mahasiswa, adalah:

$$
n=\frac{673}{1+673(0,1)^{2}}=87
$$

Berdasarkan hasil perhitungan, maka diperoleh jumlah sampel sebanyak 87 mahasiswa.

\subsection{Instrumen Penelitian}

Instrumen penelitian yang digunakan adalah kuisioner. Kuisioner yang digunakan dalam pengukuran usability adalah serangkaian kuisioner yang dapat mengolah data yang berhubungan dengan efektifitas, efisiensi, dan kepuasan dalam penggunaan sebuah sistem informasi. Hal yang mendasari penggunaan kuisioner adalah kuisioner dapat memberikan kemudahan bagi responden untuk memahami dan menjawab pertanyaan yang diajukan dengan baik. Selain itu, kuisioner membuat responden lebih nyaman dan leluasa dalam menjawab pertanyaan [13].

\subsection{Uji Kelayakan Kuisioner}

Uji kelayakan kuisioner perlu dilakukan untuk memastikan hasil pengumpulan data kuisioner telah layak digunakan untuk dianalisis. Suatu instrumen yang akan digunakan dalam penelitian harus memiliki sifat valid dan dapat diandalkan (reliable) sehingga layak digunakan sebagai suatu instrumen penelitian. Uji kelayakan kuisioner dilakukan menggunakan dua metode, yaitu uji validitas dan uji reliabilitas.

1) Uji Validitas.

Uji validitas digunakan untuk mengetahui kelayakan butir-butir dalam suatu pertanyaan dalam mendefinisikan variabel. 
Uji validitas yang digunakan adalah corellate bivariate pearson (korelasi product moment) dan $\mathrm{r}$ tabel signifikan dengan $10 \%$.

2) Uji Reliabilitas.

Uji reliabilitas dilakukan untuk mengetahui konsistensi alat ukur, dapat diandalkan dan tetap konsisten jika pengukuran tersebut dilakukan secara berulang-ulang atau tidak. Suatu instrumen dianggap reliable apabila instrumen tersebut dapat dipercaya sebagai alat ukur data penelitian. Dalam penelitian ini, uji reliabilitas dilakukan dengan menggunakan ukuran Cronbach's Alpha. Untuk mengetahui tinggi rendahnya reliabilitas instrumen digunakan kategori koefisien reliabilitas (Guilford) yang ditunjukkan pada Tabel 1 [14].

Tabel 1 Tingkat Reliabilitas

\begin{tabular}{|c|c|}
\hline Reliabilitas & Tingkat Reliabilitas \\
\hline $0,80 \leq \mathrm{r}_{11} \leq 1,00$ & sangat tinggi \\
\hline $0,60 \leq \mathrm{r}_{11}<0,80$ & tinggi \\
\hline $0,40 \leq \mathrm{r}_{11}<0,60$ & sedang \\
\hline $0,20 \leq \mathrm{r}_{11}<0,40$ & rendah \\
\hline$-1,00 \leq \mathrm{r}_{11}<0,20$ & $\begin{array}{c}\text { sangat rendah } \\
\text { (tidak reliabel) }\end{array}$ \\
\hline
\end{tabular}

\subsection{Pengukuran Usability}

Pengukuran usability dilakukan dengan menghitung persentase jawaban dari responden menggunakan rumus (3).

$\%$ Kelayakan $=\frac{\text { skor yang diobservasi }}{\text { Skor yang diharapkan }} \times 100 \%$

Data yang diperoleh kemudian dikonversi berdasarkan tabel kategori kelayakan seperti pada Tabel 2.

Tabel 2 Kategori Kelayakan [15]

\begin{tabular}{|c|c|}
\hline Angka (\%) & Klasifikasi \\
\hline$<21$ & Sangat tidak layak \\
\hline $21-40$ & Tidak layak \\
\hline $41-60$ & Cukup \\
\hline $61-80$ & Layak \\
\hline $81-100$ & Sangat layak \\
\hline
\end{tabular}

\subsection{Analisis Pengolahan Hasil Kuisioner}

Analisis hasil kuisioner dilakukan sesudah melakukan pengolahan data terlebih dahulu. Pengolahan data dilakukan setelah mendapatkan hasil uji validitas dan reliabilitas sesuai dengan ketentuan. Pengolahan data ini bertujuan untuk mengukur nilai persentase kelayakan dan mengetahui hubungan antar variabel penelitian yang ada pada kuisioner USE. Bentuk paket kuisioner USE dan pernyataan kuisioner yang telah disesuaikan dengan responden, selengkapnya dapat dilihat pada Tabel 3 .

Tabel 3 Kuisioner USE [6] Pernyataan Kuisioner

\begin{tabular}{|c|c|}
\hline \multicolumn{2}{|c|}{ Pernyataan Kuisioner } \\
\hline \multicolumn{2}{|c|}{ Usefulness } \\
\hline \multirow{2}{*}{$\mathrm{X} 1_{1}$} & It helps me be more effective. \\
\hline & Proses pengisian KRS menjadi lebih efektif. \\
\hline \multirow[b]{2}{*}{$\mathrm{X} 1_{2}$} & It helps me be more productive. \\
\hline & $\begin{array}{l}\text { Membantu proses pengisian KRS menjadi lebih } \\
\text { produktif. }\end{array}$ \\
\hline \multirow{2}{*}{$\mathrm{X} 1_{3}$} & It is useful \\
\hline & Aplikasi Pengisian KRS online sangat bemanfaat. \\
\hline \multirow[t]{2}{*}{$\mathrm{X} 1_{4}$} & $\begin{array}{l}\text { It gives me more control over the activities } \\
\text { in my life. }\end{array}$ \\
\hline & Proses perkuliahan menjadi lebih terkontrol. \\
\hline \multirow[t]{2}{*}{$\mathrm{X} 1_{5}$} & $\begin{array}{l}\text { It makes the things I want to accomplish easier to } \\
\text { get done. }\end{array}$ \\
\hline & Pengisian KRS menjadi lebih mudah dilakukan. \\
\hline \multirow{2}{*}{$\mathrm{X} 1_{6}$} & It saves me time when I use it. \\
\hline & Dapat menghemat waktu pengisian KRS. \\
\hline \multirow{2}{*}{$\mathrm{X} 1_{7}$} & It meets my needs \\
\hline & Sesuai dengan keinginan user. \\
\hline \multirow[b]{2}{*}{$\mathrm{X} 1_{8}$} & It does everything I would expect it to do. \\
\hline & $\begin{array}{l}\text { Apa yang ada di aplikasi sesuai dengan harapan } \\
\text { user. }\end{array}$ \\
\hline \multicolumn{2}{|c|}{ Ease of Use } \\
\hline \multirow{2}{*}{$\mathrm{X} 2_{1}$} & It is easy to use. \\
\hline & Mudah digunakan. \\
\hline \multirow{2}{*}{$\mathrm{X} 2_{2}$} & It is simple to use. \\
\hline & Praktis digunakan. \\
\hline \multirow{2}{*}{$\mathrm{X} 2_{3}$} & It is user friendly. \\
\hline & User friendly. \\
\hline \multirow{2}{*}{$\mathrm{X} 2_{4}$} & $\begin{array}{l}\text { It requires the fewest steps possible to } \\
\text { accomplish what I want to do with it. }\end{array}$ \\
\hline & $\begin{array}{l}\text { Butuh proses yang tidak banyak untuk } \\
\text { menyelesaikan pengisian KRS. }\end{array}$ \\
\hline \multirow{2}{*}{$\mathrm{X} 2_{5}$} & It is flexible. \\
\hline & Fleksibel. \\
\hline \multirow{2}{*}{$\mathrm{X} 2_{6}$} & Using it is effortless. \\
\hline & Menggunakannya sangatlah mudah. \\
\hline \multirow{2}{*}{$\mathrm{X} 2_{7}$} & I can use it without written instructions. \\
\hline & Dapat menggunakannya tanpa instruksi tertulis. \\
\hline \multirow[b]{2}{*}{$\mathrm{X} 2_{8}$} & I don't notice any inconsistencies as I use it. \\
\hline & $\begin{array}{l}\text { Tidak menemukan kendala saat } \\
\text { menggunakannya. }\end{array}$ \\
\hline \multirow[b]{2}{*}{$\mathrm{X} 29$} & Both occasional and regular users would like it. \\
\hline & $\begin{array}{l}\text { Mahasiswa semester awal ataupun yang sudah } \\
\text { semester lanjut pasti menyukai aplikasi ini. }\end{array}$ \\
\hline \multirow[b]{2}{*}{$\mathrm{X} 2_{10}$} & I can recover from mistakes quickly and easily. \\
\hline & $\begin{array}{l}\text { Dapat dengan mudah mengatasi kendala yang } \\
\text { terjadi. }\end{array}$ \\
\hline \multirow[b]{2}{*}{$\mathrm{X} 2_{11}$} & I can use it successfully every time. \\
\hline & $\begin{array}{l}\text { Selalu dapat menggunakannya dengan baik setiap } \\
\text { kali pengisian KRS. }\end{array}$ \\
\hline \multicolumn{2}{|c|}{ Ease of Leearning } \\
\hline \multirow{2}{*}{$\mathrm{X} 3_{1}$} & I learned to use it quickly. \\
\hline & Dapat dipelajari dengan cepat. \\
\hline & I easily remember how to use it. \\
\hline $\mathrm{X} 3_{2}$ & Mudah mengingat cara penggunaan aplikasi KRS \\
\hline & It is easy to learn to use it. \\
\hline $\mathrm{X} 3_{3}$ & Mudah mempelajari cara penggunaan aplikasi \\
\hline
\end{tabular}




\begin{tabular}{|c|c|}
\hline & KRS \\
\hline \multirow{2}{*}{$\mathrm{X} 3_{4}$} & I quickly became skillfull with it. \\
\hline & Dapat menguasai pengoperasiannya dengan cepat. \\
\hline \multicolumn{2}{|c|}{ Satisfaction } \\
\hline \multirow{2}{*}{ Y1 } & I am satisfied with it. \\
\hline & Puas dengan aplikasi KRS online. \\
\hline \multirow[b]{2}{*}{ Y2 } & I would recommend it to a friend. \\
\hline & $\begin{array}{l}\text { Akan merekomendasikan mahasiswa lain atas } \\
\text { kemudaahan penggunaannya. }\end{array}$ \\
\hline \multirow{2}{*}{ Y3 } & It is fun to use. \\
\hline & Sangat menarik untuk digunakan. \\
\hline \multirow{2}{*}{ Y4 } & It works the way I want it to work. \\
\hline & Proses kerja aplikasi sesuai keinginan user. \\
\hline \multirow{2}{*}{ Y5 } & It is wonderful. \\
\hline & Sangat memuaskan. \\
\hline \multirow{2}{*}{ Y6 } & I feel I need to have it. \\
\hline & Aplikasi ini akan selalu dibutuhkan. \\
\hline \multirow[b]{2}{*}{ Y7 } & It is pleasant to use. \\
\hline & $\begin{array}{l}\text { Aplikasi ini akan selalu memberikan kemudahan } \\
\text { user. }\end{array}$ \\
\hline \multicolumn{2}{|c|}{$\begin{array}{l}\text { Untuk keperluan analisis kuantitatif } \\
\text { penelitian, maka responden akan diberikan } \\
\text { lima alternatif jawaban dengan menggunakan } \\
\text { skala pengukuran Likert, seperti ditunjukkan } \\
\text { pada Tabel 4. }\end{array}$} \\
\hline
\end{tabular}

Tabel 4 Kriteria Pengukuran Skala Likert [16]

\begin{tabular}{|c|l|}
\hline Skor & Kriteria Jawaban \\
\hline 1 & Sangat Tidak Setuju \\
\hline 2 & Tidak Setuju \\
\hline 3 & Netral \\
\hline 4 & Setuju \\
\hline 5 & Sangat Setuju \\
\hline
\end{tabular}

Metode analisis yang digunakan untuk menganalisis data primer yang didapat dari sampel adalah dengan menggunakan metode perhitungan statistik, yaitu metode regresi linier berganda, yang terdiri atas uji korelasi regresi secara simultan (Uji F) dan uji koefisien regresi secara individu/parsial (Uji t).

\section{HASIL DAN PEMBAHASAN}

\subsection{Hasil Analisis}

Penerapan teknologi informasi di bidang akademik khususnya di perguruan tinggi sangatlah mutlak digunakan. Sebagai lembaga pendidikan tertinggi, tentunya kemajuan teknologi yang diterapkan di perguruan tinggi akan sangat berpengaruh dalam proses pendidikan. Contohnya dalam proses pengisian KRS. Dengan penerapan pengisian KRS secara online akan lebih efektif dan efisien untuk mendukung proses awal perkuliahan.

Tahap awal sistem pengisian KRS di STMIK XYZ Palembang adalah mahasiswa harus melakukan konsultasi ke dosen pembimbing akademik tentang rencana pengambilan mata kuliah. Konsultasi dengan pembimbing akademik ini dapat dilakukan secara langsung atau melalui media seperti email. Hasil konsultasi di tuliskan di Formulir Rencana Studi (FRS) dan dijadikan pedoman untuk pengisian KRS secara online. Rencana studi atau FRS diisi berdasarkan mata kuliah yang ditawarkan di semester yang akan berjalan sesuai dengan pedoman di kartu kendali akademik di setiap program studi. Pengisian harus memperhatikan jadwal yang telah dikeluarkan pihak lembaga agar jadwal tidak bertabrakan.

Berdasarkan jadwal pengisian yang telah dikeluarkan pihak lembaga, mahasiswa akan mulai mengisi KRS secara online. Setelah mahasiswa selesai melakukan pengisian KRS sesuai dengan pengisian FRS, maka dosen pembimbing akademik akan melihat hasil pengisian mahasiswa dan memastikan sudah sesuai dengan FRS untuk divalidasi.

Pemanfaatan aplikasi pengisian KRS secara online di STMIK XYZ Palembang akan dilakukan pengukuran usability. Penelitian ini menggunakan kuisioner USE sebagai parameter dalam pengukuran usability. Kuesioner USE merupakan paket kuisioner yang terdiri atas empat variabel penelitian yaitu variabel usefulness, variabel satisfaction, variabel ease of learning, dan variabel ease of use. Penelitian ini diharapkan dapat memberikan informasi serta bukti empiris tentang usability dari penggunaan sistem pengisian KRS secara online yang dapat menggambarkan sistem tersebut sudah sesuai dengan kebutuhan user sehingga dapat memberikan kepuasan terhadap user. Pengukuran dilakukan dengan membagikan kuisioner kepada 87 responden. Tetapi sebelum kuisioner dibagikan, kuesioner penelitian harus diuji terlebih dahulu melalui uji kelayakan kuisioner. Uji kelayakan kuisioner dilakukan untuk menguji kuisioner yang digunakan, telah memenuhi syarat baik atau tidak. Instrumen penelitian dapat dikatakan baik apabila telah memenuhi sifat valid dan reliabel. Oleh sebab itu, uji kelayakan kuisioner dilakukan dengan uji validitas dan reliabilitas. Setelah melakukan uji kelayakan kuisioner, maka akan dilakukan pengukuran usability dan uji regresi linier berganda untuk melihat pengaruh dari masingmasing variabel penelitian secara parsial maupun simultan. Pengujian akan dilakukan dengan perhitungan statistik menggunakan alat bantu aplikasi SPSS dan aplikasi pengolahan angka Microsoft Office Excel. 


\subsection{Karakteristik Responden}

Karakteristik responden merupakan gambaran dari keberadaan responden yang terlibat, yaitu berdasarkan jenis kelamin, program studi, dan semester. Berdasarkan data deskriptif pada Tabel 5 yang menjelaskan distribusi program studi responden, dapat diketahui bahwa responden dari program studi Sistem Informasi sebanyak 64 orang dengan persentase $73,6 \%$, program studi Teknik Informatika sebanyak 17 orang dengan persentase $19,5 \%$, dan dari program studi Komputerisasi Akuntansi sebanyak 6 orang dengan persentase $6,9 \%$ dari jumlah keseluruhan responden sebanyak 87 orang. Persentase responden program studi SI sebesar $64 \%$ menunjukkan bahwa sebagian besar responden adalah berasal dari program studi SI.

Tabel 5 Distribusi Program Studi Responden

\begin{tabular}{|c|c|c|}
\hline $\begin{array}{c}\text { Program } \\
\text { Studi }\end{array}$ & Jumlah & Persentase \\
\hline SI & 64 & $73,6 \%$ \\
\hline TI & 17 & $19,5 \%$ \\
\hline KA & 6 & $6,9 \%$ \\
\hline Total & 87 & $100 \%$ \\
\hline
\end{tabular}

Karakteristik responden berdasarkan semester dapat dilihat di Gambar 3.

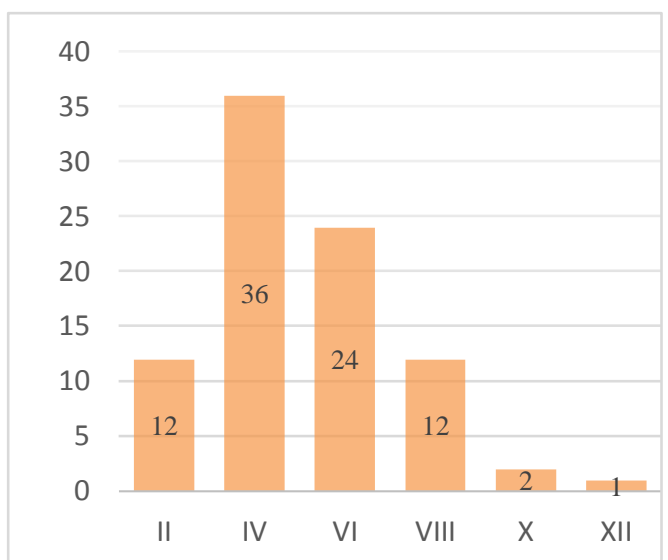

Gambar 3 Distribusi Semester Responden

Berdasarkan semester responden yang saat ini sedang ditempuh yaitu di semester genap, diketahui bahwa responden yang duduk di semester IV sebanyak 36 orang yang paling banyak mengisi kuisioner. Selanjutnya semester VI 24 orang, semster II dan VIII sebanyak 12 orang, semester $\mathrm{X}$ hanya 2 orang, dan paling sedikit 1 orang dari semester XII.

\subsection{Uji Validitas}

Uji validitas dilakukan untuk mengetahui apakah suatu instrumen alat ukur telah menjalankan fungsi ukurnya. Menurut [17], validitas menunjukkan ketepatan dan kecermatan alat ukur dalam melakukan fungsi ukurnya. Suatu skala pengukuran disebut valid bila ia melakukan apa yang seharusnya dilakukan dan mengukur apa yang harus diukur [18]. Uji validitas yang digunakan adalah corellate bivariate pearson dan $\mathrm{r}$ tabel signifikan $10 \%$. Dalam melakukan uji validitas kuisioner, jumlah reponden yang diambil biasanya minimal 30 yang mendekati kurva normal, sehingga dalam penelitian ini diambil sampel 30 orang sehingga diketahui bahwa nilai $r$ tabel sebesar 0,3061, yang berarti alat ukur dapat dinyatakan valid jika $r$ hitung lebih besar dari $r$ tabel, dan sebaliknya jika nilai $r$ hitung kurang dari $r$ tabel maka alat ukur dinyatakan tidak valid. Nilai $r$ tabel diperoleh dari tabel $r$ statistika dengan derajat bebas yang didapatkan dari jumlah responden dikurangi dua yaitu sebesar 28 dan taraf signifikansi sebesar $10 \%$. Hasil uji validitas kuisioner dapat dilihat pada Tabel 6 .

Tabel 6 Hasil Uji Validitas Kuisioner

\begin{tabular}{|c|c|c|c|c|c|}
\hline No & $\begin{array}{c}\text { Kode } \\
\text { Kuisioner }\end{array}$ & $\begin{array}{c}\mathrm{r} \\
\text { hitung }\end{array}$ & No & $\begin{array}{c}\text { Kode } \\
\text { Kuisioner }\end{array}$ & $\begin{array}{c}\mathrm{r} \\
\text { hitung }\end{array}$ \\
\hline 1 & $\mathrm{X} 1_{1}$ & 0,749 & 16 & $\mathrm{X} 2_{8}$ & 0,725 \\
\hline 2 & $\mathrm{X} 1_{2}$ & 0,782 & 17 & $\mathrm{X} 2_{9}$ & 0,811 \\
\hline 3 & $\mathrm{X} 1_{3}$ & 0,830 & 18 & $\mathrm{X} 2_{10}$ & 0,751 \\
\hline 4 & $\mathrm{X} 1_{4}$ & 0,780 & 19 & $\mathrm{X} 2_{11}$ & 0,741 \\
\hline 5 & $\mathrm{X} 1_{5}$ & 0,736 & 20 & $\mathrm{X} 3_{1}$ & 0,845 \\
\hline 6 & $\mathrm{X} 1_{6}$ & 0,750 & 21 & $\mathrm{X} 3_{2}$ & 0,880 \\
\hline 7 & $\mathrm{X} 1_{7}$ & 0,708 & 22 & $\mathrm{X} 3_{3}$ & 0,875 \\
\hline 8 & $\mathrm{X} 1_{8}$ & 0,714 & 23 & $\mathrm{X} 3_{4}$ & 0,815 \\
\hline 9 & $\mathrm{X} 2_{1}$ & 0,872 & 24 & $\mathrm{Y} 1$ & 0,895 \\
\hline 10 & $\mathrm{X} 2_{2}$ & 0,886 & 25 & $\mathrm{Y} 2$ & 0,826 \\
\hline 11 & $\mathrm{X} 2_{3}$ & 0,852 & 26 & $\mathrm{Y} 3$ & 0,904 \\
\hline 12 & $\mathrm{X} 2_{4}$ & 0,843 & 27 & $\mathrm{Y} 4$ & 0,891 \\
\hline 13 & $\mathrm{X} 2_{5}$ & 0,766 & 28 & $\mathrm{Y} 5$ & 0,894 \\
\hline 14 & $\mathrm{X} 2_{6}$ & 0,851 & 29 & $\mathrm{Y} 6$ & 0,890 \\
\hline 15 & $\mathrm{X} 2_{7}$ & 0,728 & 30 & $\mathrm{Y} 7$ & 0,911 \\
\hline
\end{tabular}

Berdasarkan hasil uji validitas kuisioner di Tabel 6, diperoleh $r$ hitung $>$ r tabel yang berarti kuisioner sebagai alat ukur dalam penelitian ini dapat dinyatakan valid.

\subsection{Uji Reliabilitas}

Uji reliabilitas dilakukan untuk mengetahui konsistensi alat ukur, dapat diandalkan dan tetap konsisten jika pengukuran tersebut dilakukan secara berulang atau tidak. Selain itu, perhitungan reliabilitas juga dilakukan 
untuk mengetahui hasil dari jawaban yang diberikan oleh responden, dapat digunakan untuk tahap pengolahan berikutnya atau tidak. Hasil uji reliabilitas dapat dilihat dari koefisien Cronbach's Alpha.

Dari hasil perhitungan dengan menggunakan SPSS, didapatkan hasil koefisien Cronbach's Alpha seperti yang disajikan pada Tabel 7.

Tabel 7 Hasil Uji Reliabilitas Kuesioner

\begin{tabular}{|c|c|}
\hline Cronbach's Alpha & Nof Items \\
\hline 0,984 & 30 \\
\hline
\end{tabular}

Uji reliabilitas ini dilakukan dengan memasukkan hasil jawaban dari seluruh pertanyaan yang valid berjumlah 30 buah dan menghasilkan nilai Cronbach's Alpha sebesar 0,984. Berdasarkan tingkat reliabilitas Cronbach's Alpha yang telah dijelaskan pada Tabel 1, nilai 0,984 berada pada range $0,80<r 11 \leq 1,00$ sehingga hasil dari pengujian menunjukkan bahwa reliabilitas dari kuesioner sangat tinggi. Jadi, komponen pertanyaan serta jawaban dapat dikatakan reliabel sehingga pengolahan data lebih lanjut dapat dilakukan.

\subsection{Pengukuran Kelayakan Usability}

Pengukuran usability dilakukan dengan menghitung persentase jawaban dari seluruh responden. Skor yang diobservasi didapatkan dari jumlah skor total seluruh jawaban dari 87 responden, yaitu sebesar 11209, sedangkan skor yang diharapkan diperoleh dari jumlah skor maksimal skala dikalikan dengan jumlah pertanyaan lalu dikalikan dengan jumlah responden, yaitu sebesar 13050 .

Setelah diketahui hasil dari skor yang diobservasi dan skor yang diharapkan, maka diperoleh hasil pengukuran berdasarkan (3) yakni sebesar $85,89 \%$. Jika hasil tersebut dihubungkan dengan interpretasi skor pada Tabel 2, nilai persentase kelayakan sebesar $85,89 \%$ berada pada interval 81 sampai $100 \%$, yang menunjukkan bahwa hasil pengukuran usability pengisian KRS secara online memiliki nilai "sangat layak".

\subsection{Analisis Pengaruh Usability}

Uji $F$ atau uji simultan digunakan untuk melihat hubungan antara independent variabel (variabel usefulness, variabel ease of use, dan ease of learning) terhadap variabel terikat (variabel satisfaction) secara bersama-sama.
Hasil perhitungan uji $\mathrm{F}$ menggunakan SPSS dapat dilihat pada Tabel 8 .

Tabel 8 Hasil Uji F
\begin{tabular}{|l|l|l|l|l|}
\hline \multicolumn{2}{|l|}{ Model } & df & F & Sig. \\
\hline \multirow{3}{*}{1} & Regression & 3 & 293,392 & $0,000^{\mathrm{a}}$ \\
\cline { 2 - 5 } & Residual & 83 & & \\
\cline { 2 - 5 } & Total & 86 & & \\
\hline
\end{tabular}

Dari Tabel 8, diketahui nilai $\mathrm{F}$ hitung sebesar 293,392 dengan derajat bebas atau df (degree of freedom) regression sebesar 3 yang didapatkan dari jumlah variabel bebas yang digunakan dan df residual sebesar 83 yang diperoleh dari jumlah sampel dikurangi jumlah variabel. Sedangkan diketahui nilai $\mathrm{F}$ tabel sebesar 2,15 dengan taraf signifikansi $10 \%$. Karena $F$ hitung lebih besar dari $F$ tabel $(293,392>2,15)$ dan nilai signifikansinya kurang dari $0,1(0,000<0,1)$, maka disimpulkan bahwa secara simultan, variabel usefulness, ease of use, dan ease of learning berpengaruh secara signifikan terhadap variabel satisfaction dalam hal penggunaan aplikasi pengisian KRS secara online di STMIK XYZ Palembang.

Uji $\mathrm{t}$ atau uji parsial digunakan untuk mengetahui hubungan antara variabel usefulness, variabel ease of use, dan variabel ease of learning terhadap variabel satisfaction secara parsial.

Tabel 9 Hasil Uji t

\begin{tabular}{|l|l|c|c|c|}
\hline \multicolumn{2}{|c|}{ Model } & B & t & Sig. \\
\hline \multirow{3}{*}{1} & (Constant) & $-1,790$ & $-1,523$ & 0,132 \\
\cline { 2 - 5 } & $\mathrm{X}_{1}$ & 0,330 & 5,057 & 0,000 \\
\cline { 2 - 5 } & $\mathrm{X}_{2}$ & 0,386 & 6,690 & 0,000 \\
\hline & $\mathrm{X}_{3}$ & 0,129 & 1,046 & 0,299 \\
\hline
\end{tabular}

Berdasarkan Tabel 9, maka model regresi tersebut dapat dianalisis berdasarkan koefisienkoefisiennya yaitu:

$$
Y=-1,79+0,33 X_{1}+0,386 X_{2}+0,129 X_{3}
$$
dengan:

$\mathrm{Y}=$ Variabel Satisfaction

$\mathrm{X}_{1}=$ Variabel Usefulness

$\mathrm{X}_{2}=$ Variabel Ease of Use

$\mathrm{X}_{3}=$ Variabel Ease of Learning

Dari Tabel 9, didapatkan nilai t hitung untuk variabel usefulness sebesar 5,057, variabel ease of use sebesar 6,69, dan variabel ease of learning sebesar 1,046. Sedangkan nilai $\mathrm{t}$ tabel diperoleh dari tabel distribusi $\mathrm{t}$ dengan melihat nilai df dan taraf signifikansi dibagi dua. Nilai df diperoleh dari jumlah sampel 
dikurangi jumlah variabel bebas kemudian dikurangi satu, yaitu sebesar 83, dan taraf signifikansi dibagi dua, menjadi 0,05 , sehingga diketahui nilai t tabel sebesar 1,663. Sedangkan nilai signifikansinya dari konstanta sebesar 0,132, variabel usefulness sebesar 0,000, variabel ease of use sebesar 0,000 dan variabel ease of learning sebesar 0,299.

\subsection{Pengujian Hipotesis}

Berdasarkan rumusan awal hipotesis penelitian, ditentukan bahwa untuk menguji kebenaran hipotesis, dilakukan uji $\mathrm{F}$ (uji simultan) yakni dengan membandingkan nilai $\mathrm{F}$ hitung dengan $\mathrm{F}$ tabel. Apabila nilai F hitung lebih besar dari $F$ tabel dan tingkat signifikansinya kurang dari 0,1, maka persamaan regresi dan koefisien korelasinya signifikan sehingga $\mathrm{H}_{0}$ ditolak dan hipotesis tersebut diterima. Hal ini menunjukkan ada pengaruh yang signifikan antara variabel bebas terhadap variabel terikat dan sebaliknya.

Hasil pengujian untuk keempat hipotesis penelitian ini diperoleh:

1) Pengujian Hipotesis $1\left(\mathrm{H}_{1}\right)$

$\mathrm{H}_{0}$ : Tidak ada pengaruh yang signifikan antara variabel bebas, yaitu variabel usefulness, variabel ease of use, dan variabel ease of learning terhadap variabel terikat yaitu variabel satisfaction.

$\mathrm{H}_{1}$ : Ada pengaruh yang signifikan antara variabel bebas yaitu variabel usefulness, variabel ease of use, dan variabel ease of learning terhadap variabel terikat yaitu variabel satisfaction yang dilakukan secara simultan.

Dari uji $\mathrm{F}$ yang telah dilakukan, diperoleh fakta bahwa nilai $F$ hitung adalah sebesar 293,392 dan F tabel sebesar 2,15, sehingga diketahui nilai $\mathrm{F}$ hitung lebih besar dari $\mathrm{F}$ tabel. Sedangkan taraf signifikansinya sebesar 0,000 yang berarti kurang dari 0,1. Hal ini membuktikan bahwa $\mathrm{H}_{0}$ ditolak dan $\mathrm{H}_{1}$ diterima, yang berarti ada pengaruh signifikan antara variabel usefulness, variabel ease of use, dan variabel ease of learning terhadap variabel satisfaction yang dilakukan secara simultan (bersama-sama) dalam hal penggunaan aplikasi pengisian KRS secara online di STMIK XYZ Palembang.

2) Pengujian Hipotesis $2\left(\mathrm{H}_{2}\right)$
$\mathrm{H}_{0}$ : Tidak ada pengaruh yang signifikan antara variabel usefulness terhadap variabel satisfaction.

$\mathrm{H}_{2}$ : Ada pengaruh yang signifikan antara variabel usefulness terhadap variabel satisfaction.

Dari uji t yang telah dilakukan untuk membuktikan hipotesis 2, diperoleh fakta bahwa variabel $X_{1}$ (usefulness) berpengaruh secara signifikan terhadap variabel satisfaction secara parsial, karena nilai $\mathrm{t}$ hitung yang didapatkan, yaitu 5,057, lebih besar daripada $\mathrm{t}$ tabel, yaitu 1,663, dan tingkat signifikansi sebesar 0,000 kurang dari 0,1 . Ini menunjukkan bahwa $\mathrm{H}_{0}$ ditolak dan $\mathrm{H}_{2}$ diterima. Artinya ada pengaruh signifikan antara variabel usefulness, terhadap variabel satisfaction dalam hal penggunaan aplikasi pengisian KRS secara online di STMIK XYZ Palembang.

3) Pengujian Hipotesis $3\left(\mathrm{H}_{3}\right)$

$\mathrm{H}_{0}$ : Tidak ada pengaruh yang signifikan antara variabel ease of use terhadap variabel satisfaction.

$\mathrm{H}_{3}$ : Ada pengaruh yang signifikan antara variabel ease of use terhadap variabel satisfaction.

Dari hasil pengujian secara parsial yang telah dilakukan untuk membuktikan hipotesis 3 , diketahui bahwa nilai t hitung sebesar 6,69 dan t tabel sebesar 1,663. Sedangkan tingkat signifikansinya adalah 0,000. Hal tersebut menunjukkan bahwa $\mathrm{H}_{0}$ ditolak dan $\mathrm{H}_{3}$ diterima yang berarti secara parsial variabel $\mathrm{X}_{2}$ (ease of use) berpengaruh secara signifikan terhadap variabel Y (satisfaction) dalam hal penggunaan aplikasi pengisian KRS secara online di STMIK XYZ Palembang.

4) Pengujian Hipotesis $4\left(\mathrm{H}_{4}\right)$

$\mathrm{H}_{0}$ : Tidak ada pengaruh yang signifikan antara variabel ease of use terhadap variabel satisfaction.

$\mathrm{H}_{4}$ : Ada pengaruh yang signifikan antara variabel ease of use terhadap variabel satisfaction.

Dari hasil pengujian secara parsial, diketahui bahwa nilai t hitung sebesar 1,046 dan $\mathrm{t}$ tabel sebesar 1,663. Sedangkan tingkat signifikansinya adalah 0,299 lebih dari 0,1 . Hal ini menunjukkan bahwa $\mathrm{H}_{0}$ diterima dan $\mathrm{H}_{4}$ ditolak yang berarti secara parsial variabel $\mathrm{X}_{3}$ (ease of learning) tidak berpengaruh secara signifikan terhadap variabel kepuasan (satisfaction). 
Sedangkan untuk konstanta (B), tingkat signifikansinya 0,132 lebih dari 0,1 juga tidak berpengaruh ke persamaan regresi, sehingga peersamaan regresi:

$$
Y=0,33 X_{1}+0,386 X_{2}
$$

Persamaan regresi tersebut menunjukkan bahwa konstanta dan variabel ease of learning tidak dapat berdiri sendiri seperti variabel usefulness dan ease of use.

\subsection{Analisis Variabel yang Dominan}

Variabel yang paling dominan dalam penelitian ini dapat dilihat pada Gambar 4.

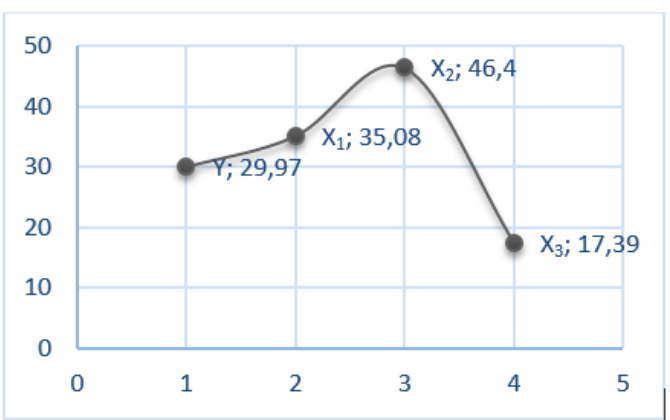

Gambar 4 Rata-Rata Nilai Variabel

Grafik pada Gambar 4 menunjukkan bahwa nilai rata-rata variabel yang paling rendah terletak pada variabel ease of learning, sedangkan rata-rata nilai variabel yang paling tinggi adalah variabel ease of use. Variabel ease of learning dengan rata-rata nilai paling rendah sebesar 17,39 disebabkan oleh perbedaan kemampuan responden dalam mempelajari aplikasi pengisian KRS. Sedangkan variabel ease of use yang memiliki rata-rata-nilai tertinggi dari variabel yang lain dengan nilai rata-rata 46,4 disebabkan oleh pengalaman responden dalam merasakan kemudahan saat menggunakan aplikasi tersebut.

\section{PENUTUP}

Penelitian menganalisis usability aplikasi pengisian KRS online di STMIK XYZ Palembang ini membuktikan hipotesis bahwa ada pengaruh yang signifikan secara simultan atau bersama-sama antara setiap variabel bebas terhadap variabel terikat. Variabel bebas yang terdiri dari variabel variabel usefulness, variabel ease of use, dan variabel ease of learning sedangkan variabel terikat yaitu satisfaction. Sedangkan, jika dilihat dari pengujian secara parsial/individual, hanya variabel usefulness dan ease of use yang berpengaruh terhadap variabel satisfaction.

Jadi, secara keseluruhan aplikasi pengisian KRS secara online di STMIK XYZ telah cukup baik dan berdampak terhadap kepuasan user yaitu mahasiswa. Tetapi yang perlu ditingkatkan tentunya minat dari user untuk mempelajari dan memberikan koreksi atas kekurangan aplikasi tersebut agar menjadi lebih baik lagi. Untuk itu, disarankan penelitian lanjutan agar tidak hanya user dari mahasiswa sebagai pengguna utama, tetapi juga dapat ditinjau dari para dosen pembimbing akademik yang terlibat secara tidak langsung di aplikasi.

\section{DAFTAR PUSTAKA}

[1] Akhmadzain. Analisis Usability Test Terhadap Tampilan ATM konvensional BCA, Mandiri dan BNI. Konferensi Nasional Sistem dan Informatika. 2008.

[2] International Organization for Standardization. ISO 9241-11: Guidance on Usability. 1998.

[3] Dumas, Redish,.,et al., Apractical guide to Usability Testing. John Wiley \& Sons. 1999.

[4] Hidayat, W., Ranius, Y. Ependi, U. Penerapan Metode Usability Testing Pada Evaluasi Situs Web Pemerintahan Kota Prabumulih. Jurnal Teknik Informatika. 2014.

[5] Munaiseche, C.P. Pengujian Web Aplikasi Dss Berdasarkan Pada Aspek Usability. ORBITH. 8 (2). pp. $63-68.2012$.

[6] Jacob, Nielsen. Usability 101: Introduction to Usability. diakses dari https://www.nngroup.com, pada tanggal 5 Maret 2019.

[7] Aelani, Khoirida, Falahah, Pengukuran Usability Sistem menggunakan USE Questionnaire (Studi Kasus Aplikasi Perwalian Online STMIK "AMIKBANDUNG", SNATI, Yogyakarta, 2012.

[8] Tullis, Tom, and Albert, Bill. Measuring The User Expperience. Morgan Kaufmann. 2008.

[9] Perlmann, Gary. User Interface Usability Evaluation with Web Based Questionnaire. diakses dari 
https://garyperlman.com/quest/ pada tanggal 7 Maret 2019

[10] Sugiyono, Metode Penelitian Pendidikan (Pendekatan Kuantitatif, Kualitatif, dan R\&D). Bandung: Alfabeta. 2011.

[11] Sahfitri, Vivi dan Ulfa, Maria. Evaluasi Usability Sistem E-Learning sebagai Aplikasi Pendukung Proses Pembelajaran di Perguruan Tinggi Menggunakan USE Questionnaire. Jurnal Ilmiah MATRIK. Vol. 17 No. 1 pp. 53-66. 2015.

[12] Kusuma, Wahyu Andhika, dkk. Analisis Usability dalam User Experience pada Sistem KRS-Online UMM menggunakan USE Questionnaire. JNTETI. Vol 5 No. 4. November 2016.

[13] Munir, Penggunaan Learning Management System (LMS) di Perguruan Tinggi: Studi Kasus di Universitas Pendidikan Indonesia, Jurnal Cakrawala Pendidikan. tahun XXI X, no.1. pp.109-119. 2010.

[14] Penjelasan Uji Reliabilitas Instrumen Lengkap, diakses dari website https://www.statistikian.com/2012/1 0/uji-reliabilitas-instrumen pada tanggal 7 Maret 2019.

[15] Suharsimi Arikunto \& Cepi S.A.J. Evaluasi Program Pendidikan, Jakarta: Bumi Aksara. 2009.

[16] Sugiyono. Metode Penelitian Pendidikan, Bandung: Alfabeta. 2010.

[17] Sekaran, Uma. Research Methods for business: Skill-Building Approach. fourth edition. New York: John Wiley \& Sons Inc. 2003.

[18] Wijaya, Tony. Cepat Menguasai SPSS 19 untuk Olah dan Interpretasi, Cahaya Atma, Kelompok Penerbit Univ. Atmajaya Yogyakarta. Cetakan ke-5. 2015. 
